\title{
Adult-onset Alexander disease: could facial myokymia be a symptom?
}

Doença de Alexander de início no adulto: mioquimia facial pode ser sintoma?

Rosana Herminia Scola, Paulo J. Lorenzoni, Cláudia S. K. Kay, Lineu C. Werneck

A 24-year-old man presented with progressive cerebellar syndrome, which after six months evolved with dysphagia, dysphonia, corticospinal tract involvement and facial myokymia. Electromyography showed myokymic discharges (Figure). Brain and spinal cord magnetic resonance imaging (MRI) were suggestive of Alexander disease (AD) (Figure). Genetic analysis in GFAP gene confirmed AD (Asp360Asn).
Adult-onset $\mathrm{AD}$ diagnoses can be strongly suggested by MRI findings ${ }^{1,2,3,4}$. Electromyography can usually revealed mild chronic neurogenic abnormalities or myoclonus rhythm in some patients ${ }^{1}$. Myokymia has not been reported associated to $\mathrm{AD}^{1,4}$. However, facial myokymia although typically a benign condition, may reflect the brainstem evolvement of the $\mathrm{AD}$. Therefore, our case includes myokymia in
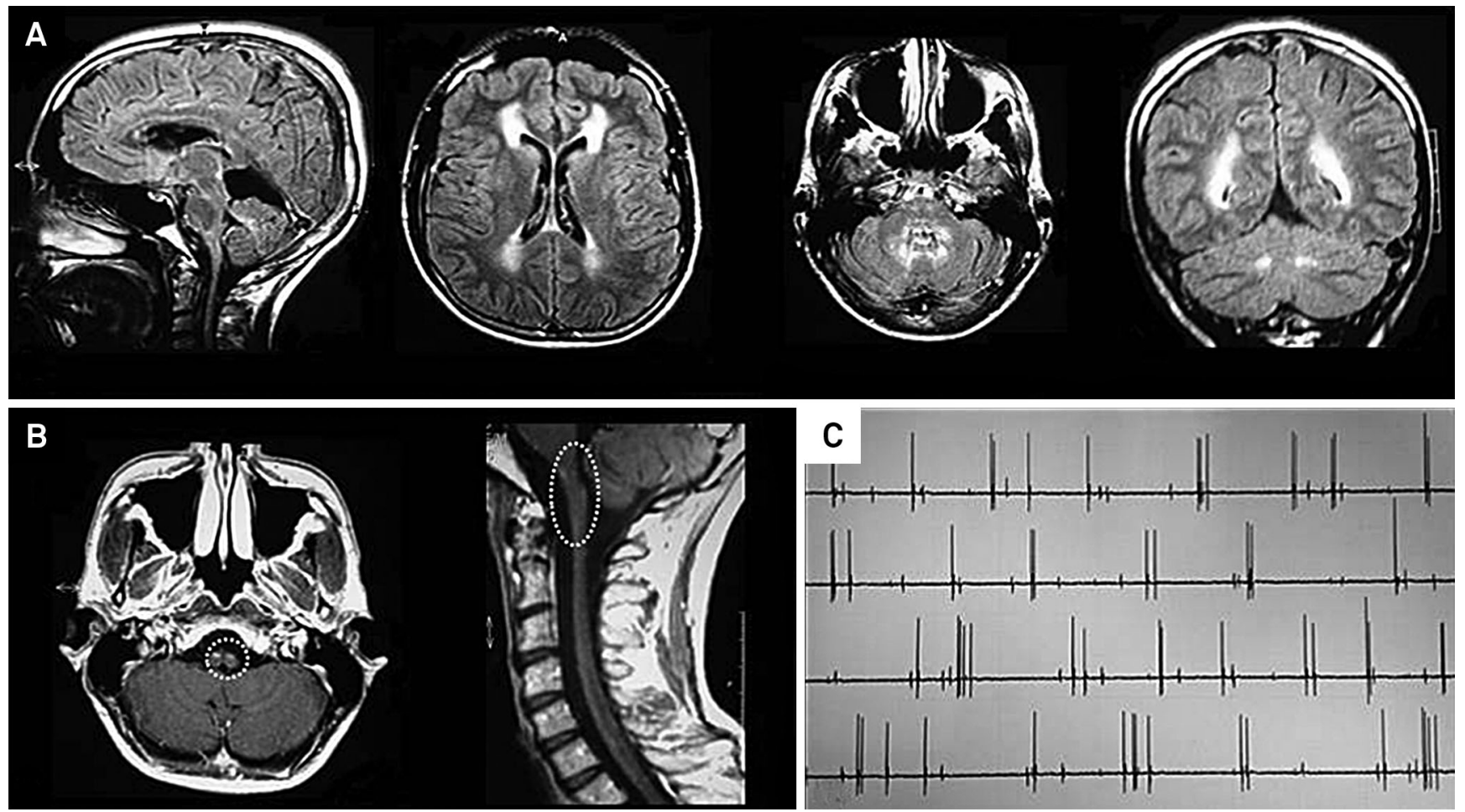

Figure. Brain and spinal cord magnetic resonance imaging studies showed: (A) infratentorial and upper cervical spinal cord atrophy (especially in medulla oblongata) with symmetrical areas of high signal on FLAIR images in the periventricular white matter of the brain hemispheres, brainstem and cerebellum; and (B) T1-weighted images following gadolinium contrast showing mild enhancement in medulla oblongata and upper cervical spinal cord (circles); and (C) Needle electromyography showed myokymic discharge characterized by groups of single or few spikes firing repetitively in a burst, recurring at intervals that are semirhythmic, in left orbicularis oris muscle (200uV/0.2seg).

Serviço de Neurologia, Departamento de Clínica Médica, Hospital de Clínicas, Universidade Federal do Paraná, Curitiba PR, Brazil.

Correspondence: Rosana H. Scola; Serviço de Neurologia, Hospital de Clínicas, Universidade Federal do Paraná; Rua General Carneiro, 181 / $3^{\circ}$ andar; 80060 900 Curitiba PR, Brasil; E-mail: rosana.scola@hc.ufpr.br

Conflict of interest: There is no conflict of interest to declare.

Received 13 June 2014; Received in final form 30 July 2014; Accepted 18 August 2014 
the clinical and electrophysiological characteristics of the adult-onset $\mathrm{AD}$, as well as, $\mathrm{AD}$ in the differential diagnosis of facial myokymia.

\section{Acknowledgments}

Gajja S. Salomons and Marjo S. van der Knaap for their collaboration in the radiological and genetic analysis.

\section{References}

1. Pareyson D, Fancellu R, Mariotti C, Romano S, Salmaggi A, Carella F et al. Adult-onset Alexander disease: a series of eleven unrelated cases with review of the literature. Brain. 2008;131(Pt 9):2321-31. htpp://dx.doi.org/10.1093/brain/awn178

2. Knaap MS, Naidu S, Breiter SN, Blaser S, Stroink H, Springer S et al. Alexander disease: diagnosis with MR imaging. AJNR Am J Neuroradiol. 2001;22(3):541-52.
3. Rezende SAS, Fernandes M, Munhoz RP, Raskin S, Schelp AC, Knaap MS et al. Cerebellar ataxia as the first manifestation of Alexander's disease. Arq Neuropsiquiatr. 2012;70(5):309-10. http://dx.doi.org/ 10.1590/S0004-282X2012000400018

4. Balbi P, Salvini S, Fundarò C, Frazzitta G, Maestri R, Mosah D et al. The clinical spectrum of late-onset Alexander disease: a systematic literature review. J Neurol. 2010;257(12):1955-62. http://dx.doi.org/ 10.1007/s00415-010-5706-1 